\title{
THE EFFECT OF HYPOTHERMIA ON ATRIAL FIBRILLATION AND OTHER ARRHYTHMIAS
}

\author{
BY \\ WALTER SOMERVILLE \\ From the Department of Cardiology, the Middlesex Hospital \\ Received November 12, 1959
}

The changes produced by hypothermia on the cardiac rate and rhythm have been well documented in the normal (Emslie-Smith, 1956) and abnormal heart (Hicks et al., 1956; Graham, 1957). The observations recorded have in the main dealt with normal sinus rhythm although reference has been made to the effects of cooling on atrial fibrillation (Fleming and Muir, 1957). The changes in this and other arrhythmias have become better known within the past few years as experience with hypothermia has widened. This paper reports the effects of surface hypothermia on four different types of cardiac arrhythmias that were present before hypothermia was induced.

Amongst the first 150 patients operated on for different types of heart disease under hypothermia at the Middlesex Hospital, there were 13 with atrial fibrillation, 2 with atrial flutter, 2 with atrioventricular dissociation, and 1 with multiple ectopic ventricular beats. The immersion technique for hypothermia (Sellick, 1957) was used, the temperature aimed at being $30^{\circ} \mathrm{C}$. although in some cases it fell to $29^{\circ} \mathrm{C}$. Lead II of the electrocardiogram was recorded at each $1^{\circ} \mathrm{C}$. fall in œsophageal temperature or more frequently if the need arose. A number of drugs were used routinely for pre-medication or anæsthesia, namely promethazine, pethedine, scopolamine, thiopentone, succinyl-choline, tubocurarine, nitrous oxide, oxygen, and ether, but it is almost certain that these drugs had little if any influence on the rhythm changes to be described, which were thought to be exclusively the effects of hypothermia.

\section{Atrial Fibrillation}

Observations were made on 13 patients with established atrial fibrillation: all had atrial septal defects and 7 had mitral stenosis in addition. The majority were over 40 years of age: 7 were in the fifth decade, 3 in the sixth, and the remaining 3 under 40 . The earliest changes were slowing of the atrial fibrillation rate and of the ventricular rate, these occurring after $1^{\circ}-3^{\circ} \mathrm{C}$. fall in temperature. The degree of slowing with falling temperature is shown in Fig. 1.

The ventricular rhythm became precisely regular after $1^{\circ}-3^{\circ} \mathrm{C}$. fall in 9 of the 13 patients, the atria continuing to fibrillate: Fig. 2 illustrates a typical instance. The QRS shape remained unchanged between the temperature range of $37^{\circ}-35^{\circ} \mathrm{C}$. Below $31^{\circ} \mathrm{C}$., the QRS complex often became wide or notched and changed shape as shown in Fig. 3.

Atrial fibrillation, which had been established for at least two years, was temporarily abolished and sinus or nodal rhythm restored in three patients. The temperatures at which this occurred were $30.2^{\circ} \mathrm{C}$, $30.4^{\circ} \mathrm{C}$. and $31.7^{\circ} \mathrm{C}$, , before the atrium was opened. Sinus or nodal rhythm remained for only a few minutes in two of these and for 28 minutes in the third before atrial fibrillation returned (Fig. 4). Established atrial fibrillation was not a predisposing cause of ventricular fibrillation in the temperature range $37^{\circ}-30^{\circ} \mathrm{C}$. Ventricular fibrillation occurred in two cases during or after circulatory occlusion, but air bubbles were seen in a coronary artery in each case, a well-known exciting cause of ventricular fibrillation. 


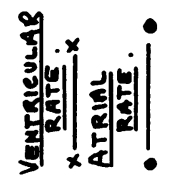

$40320-$

$60280-$

$55260-$

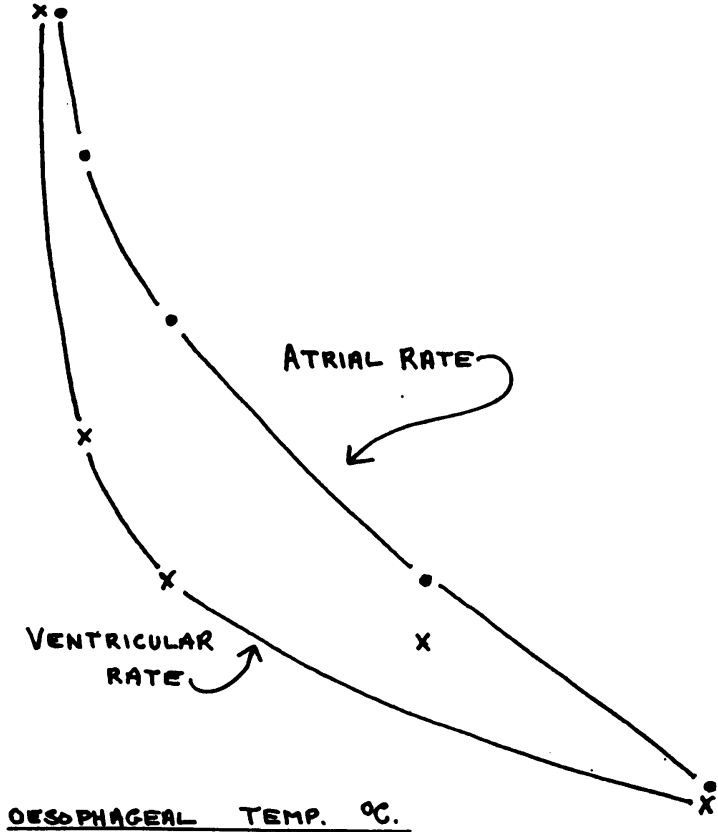

45220

40. 2001

38

34
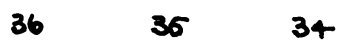

33

32

Fig. 1.-Atrial fibrillation: effect of hypothermia on atrial and ventricular rates.

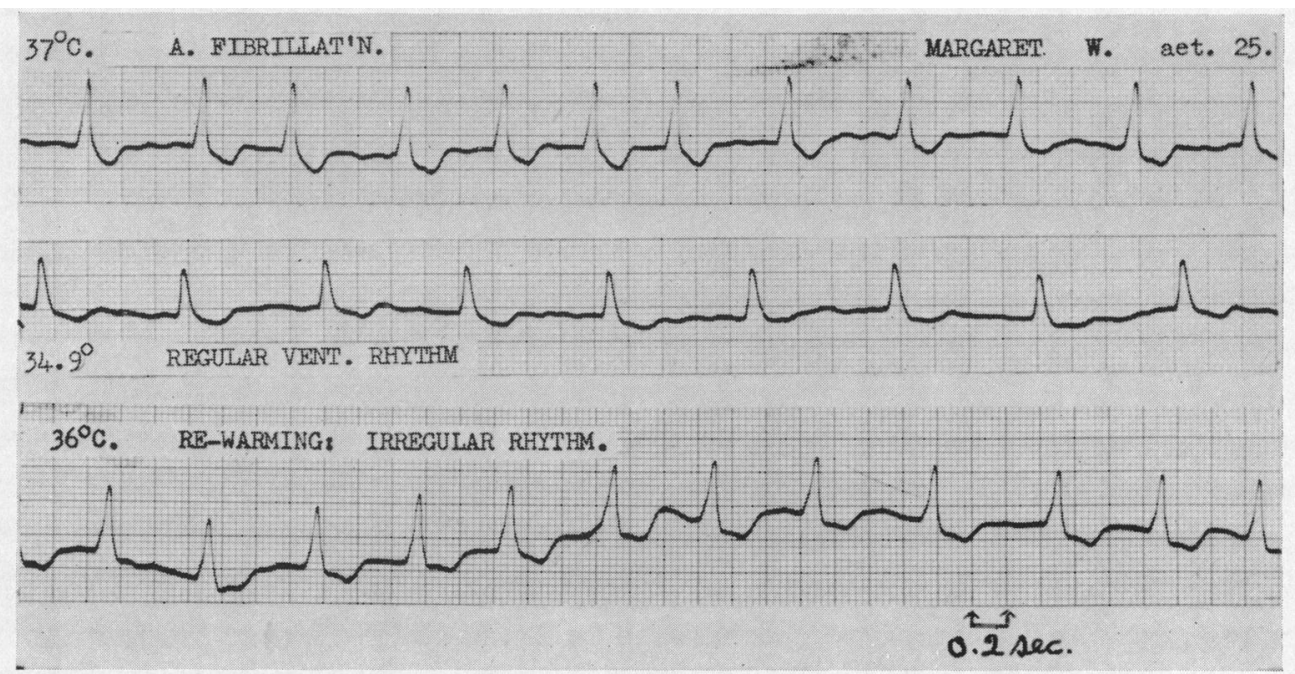

Fig. 2.-Atrial fibrillation. When the œesophageal temperature fell from $37^{\circ}$ to $34.9^{\circ} \mathrm{C}$, the ventricular rate slowed from 94 to 77 a minute and the rhythm became precisely regular. Irregular ventricular rhythm returned on re-warming. Lead II is recorded in this and all subsequent electrocardiograms. Time marking shown is the same in all illustrations, 0.2 and 0.04 sec. 


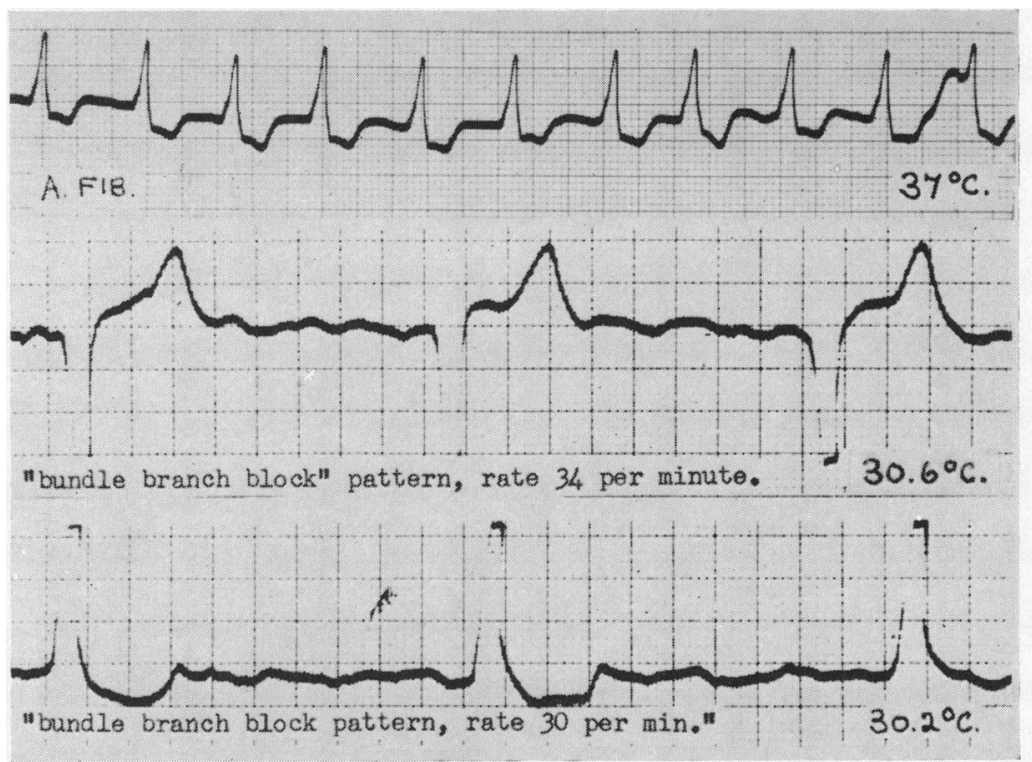

FIG. 3.-Atrial fibrillation. At $30.6^{\circ} \mathrm{C}$., QRS has become wide $(0 \cdot 14 \mathrm{sec}$.) and changed its shape, resembling the pattern of bundle-branch block. A few minutes later (lowest strip), the rate has fallen from 34 to 30 a minute, and the altered shape of QRS suggests a different ventricular pace-make or a spread of the conduction defect.

During re-warming, the series of events described above occurred in roughly the reverse order to their appearance.

\section{OTHER ARRHYTHMIAS}

Atrial Flutter. Two patients were studied where atrial flutter had persisted since closure of an atrial septal defect 7 months and 9 months previously, despite all efforts to correct it, including full digitalization. In the first, a boy aged 11, the initial rhythm was atrial flutter with 2 to 1 block: within a minute of immersion in water at $9^{\circ} \mathrm{C}$., and before the osophageal temperature had fallen from $37 \cdot 3^{\circ}$ C., 1-to-1 conduction developed. Pronestyl (procaine amide) was given immediately and quickly produced atrioventricular block varying between 2-to-1 and 3-to-1. Sinus rhythm returned when the temperature was $31^{\circ} \mathrm{C}$. (Fig. 5), before the right atrium was opened, and has remained up to the present time, a period of 15 months.

In the second, a man aged 39, the defect had been completely repaired but atrial flutter persisted. Troublesome palpitation with a pulse rate of 120 to 140 occurred with effort or excitement despite full digitalization. All attempts to abolish the flutter having failed, hypothermia to $30^{\circ} \mathrm{C}$. was induced in the hope that the experience with the previous patient would be repeated. The ventricular rate slowed with alteration of A-V block from 2-to-1 to 3- or 4-to-1, and the flutter rate decreased but was not abolished at any stage of cooling or re-warming. Pronestyl and quinidine both failed to restore sinus rhythm.

Atrio-ventricular Dissociation. Two examples of atrio-ventricular dissociation are shown in Fig. 6 and 7. Both were patients with atrial septal defect. Sinus rhythm returned in one, a girl aged 24 with an atrial septal defect, when the œsophageal temperature fell to $35^{\circ} \mathrm{C}$., and in the other, a girl aged 13 with pulmonary stenosis, immediately after immersion.

Premature Beats. Multiple premature ventricular beats arising from at least two different foci were a feature of the rhythm of a man, aged 47 , with severe pulmonary stenosis: they were improved 


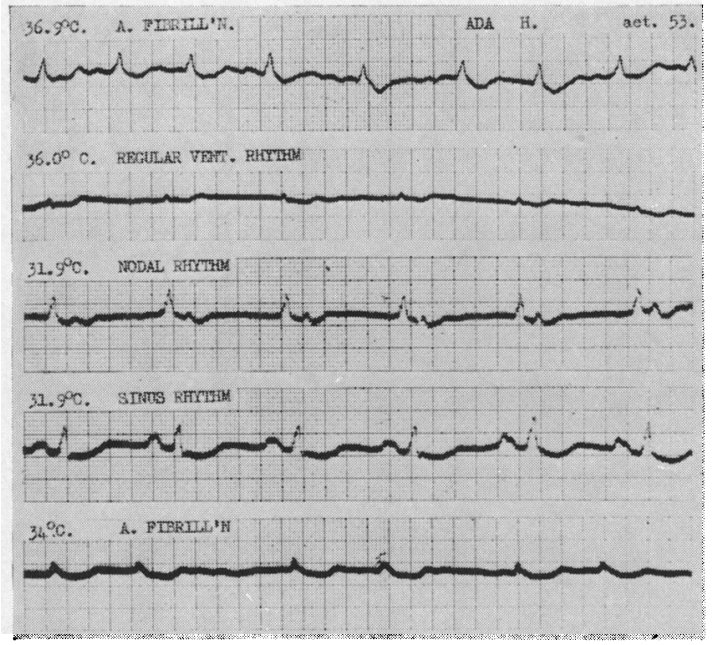

Fig. 4.-Atrial fibrillation at normal body temperature. When the osophageal temperature fell to $36^{\circ} \mathrm{C}$. after immersion, the ventricular rhythm became precisely regular while the atria continued to fibrillate. At $31.9^{\circ} \mathrm{C}$., nodal rhythm appeared followed by sinus rhythm, which persisted for 28 minutes. Atrial fibrillation returned on re-warming.

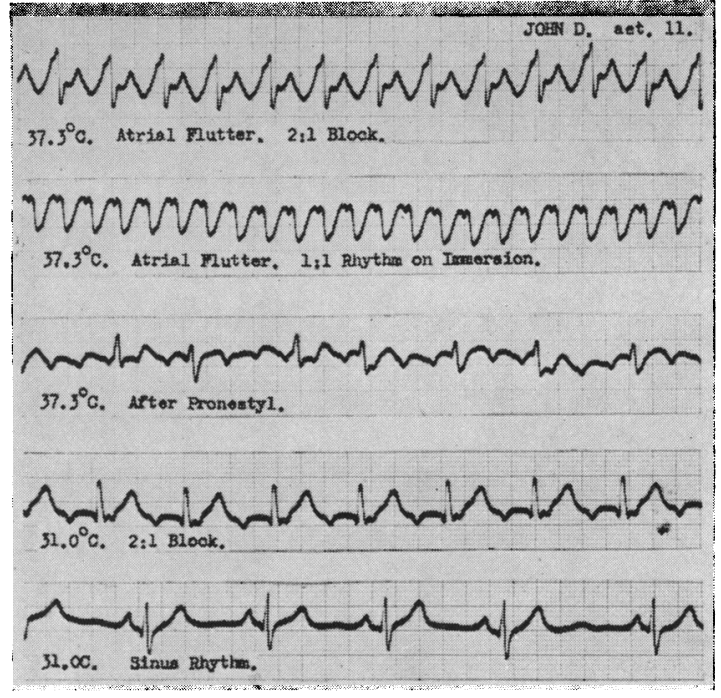

Fig. 5.-Atrial flutter with 2-1 block. Normal sinus rhythm returned abruptly at $31^{\circ} \mathrm{C}$. before the right atrium was incised.

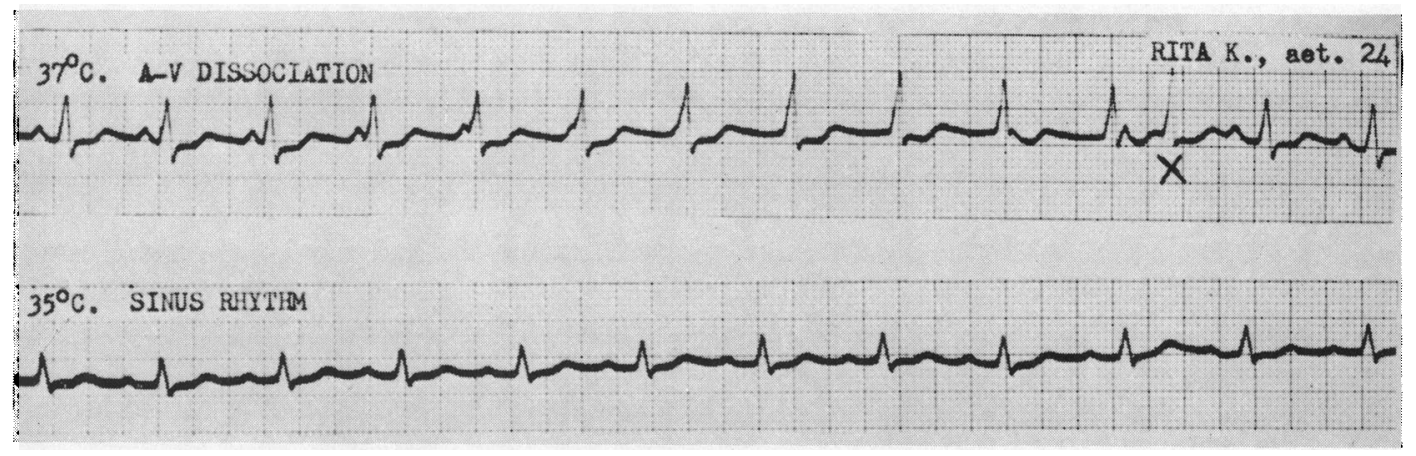

Fig. 6.-Atrio-ventricular dissociation at normal body temperature. The complex marked $\mathrm{X}$ is an example of interference with aberrant ventricular conduction. When the osophageal temperature fell to $35^{\circ} \mathrm{C}$., sinus rhythm appeared.

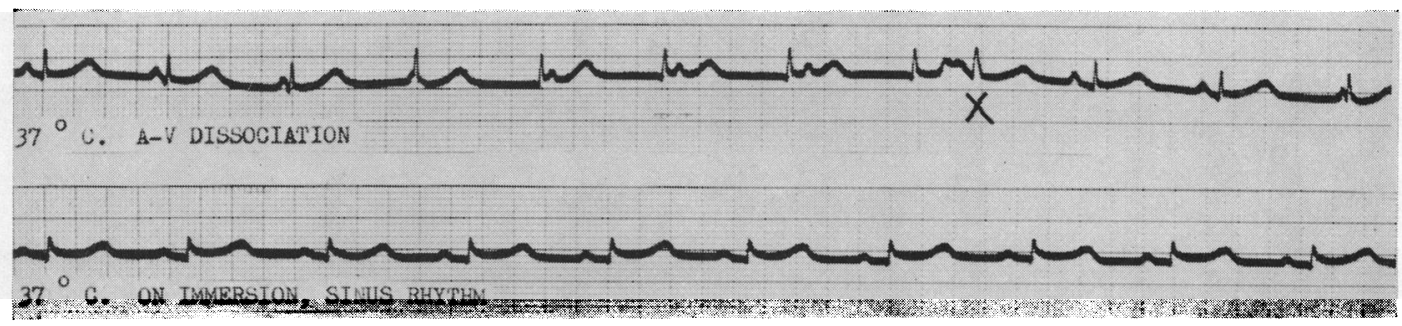

FIG. 7.-Atrio-ventricular dissociation. Normal conduction was restored on immersion before the œsophageal temperature had fallen. An interference beat is marked X. 
but not abolished by digitalis and quinidine. When hypothermia was induced for pulmonary valvotomy, the ectopic beats disappeared when the temperature fell from $37 \cdot 8^{\circ}$ to $36^{\circ} \mathrm{C}$. and did not reappear after operation when the normal body temperature returned (Fig. 8).

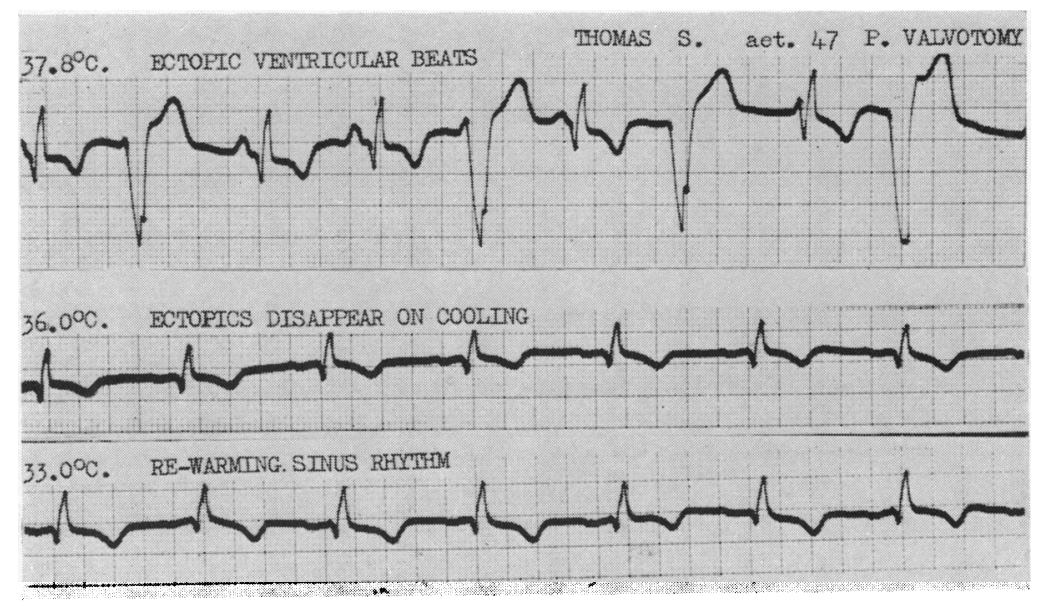

FIG. 8.-Multiple premature (ectopic) ventricular beats disappearing when the temperature fell from $37 \cdot 8^{\circ}$ to $36^{\circ} \mathrm{C}$.

\section{Discussion}

The effect of hypothermia on cardiac arrhythmias has been given little attention. The reason is that patients with arrhythmias, and particularly atrial fibrillation, are seldom candidates for surgical treatment under hypothermia. Atrial septal defect is the only condition amenable to this type of surgery in which atrial fibrillation is relatively common. When mitral stenosis is also present (Lutembacher's syndrome), the incidence is comparatively high: 7 of the 13 patients in the present series with atrial septal defect and established atrial fibrillation had also mitral stenosis. Four patients with atrial fibrillation were included in the 25 studied electrocardiographically by Fleming and Muir (1957), but beyond stating that those who developed atrial fibrillation during hypothermia tolerated the procedure well, these authors do not dwell on the subject.

A consistency in the behaviour of the cardiac rhythm as the body temperature fell was apparent in all the patients with atrial fibrillation. The ventricular rhythm became precisely regular between $37^{\circ}$ and $35^{\circ} \mathrm{C}$. in 9 of the 13 patients, the atria continuing to fibrillate. The regularity appeared in one instance immediately on immersion, before any temperature fall was recorded. Another became regular after a fall of $0.5^{\circ} \mathrm{C} .:$ the ventricular rate continued to slow as the temperature was lowered. The configuration of QRS remained unchanged, suggesting that the ventricular pacemaker was above the bifurcation of the bundle of His. When the rate fell to 25 to 35 a minute, sometimes QRS became wide and notched resembling the pattern of bundle-branch block, a change that may also occur when the initial rhythm is sinus. It suggests that either the pacemaker had descended into one or other branch of the bundle of His or a further degree of disturbance of conduction now involved a bundle branch (Schott, 1959). Such a pattern is shown in Fig. 3. It was most commonly recorded when the circulation was occluded and in those circumstances probably represents the added effects of anoxia. With re-warming, the ventricular rate gradually increased and the QRS resumed its original shape. The rhythm became irregular again at temperatures that varied from case to case, usually $35^{\circ}-36^{\circ} \mathrm{C}$. Atropine increased the rate and restored irregularity immediately (Fig. 9). While the explanation of these phenomena is not clear, cold seems to induce a block that insulates the atrio-ventricular node and junctional tissues from atrial 


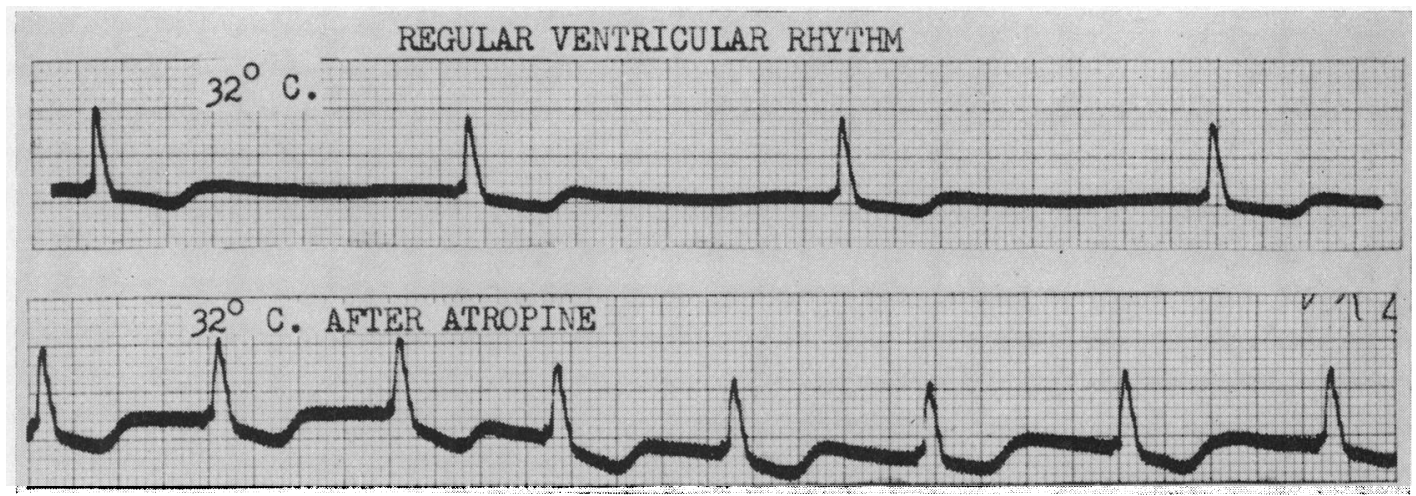

FIG. 9.-The effect of atropine on atrial fibrillation with regular ventricular rhythm during hypothermia. Atropine immediately doubled the ventricular rate and the rhythm became irregular. A second figure showing just the same effect has been omitted.

stimuli. The instantaneous effect of atropine suggests that it is a chemical block mediated by acetylcholine or a similar substance.

One-to-one conduction appeared instantly when a boy with atrial flutter and 2-to-1 block was immersed in cold water. Digitalis had already failed to revert the rhythm but the usual maintenance dose had been continued. Pronestyl promptly produced atrio-ventricular block. Both atrial and ventricular rates fell as usual with cooling and sinus rhythm occurred at $31^{\circ} \mathrm{C}$.

There are reasonable theoretical grounds for explaining the reversion of atrial fibrillation and flutter to sinus rhythm by hypothermia. Ventricular fibrillation induced in the isolated rabbit heart perfused with Ringer's solution at $37^{\circ} \mathrm{C}$. reverts to sinus rhythm at $32^{\circ} \mathrm{C}$. and passes into fibrillation again as the temperature rises (Burn and Goodford, 1957). Similarly, atrial fibrillation in the isolated atria in Ringer's solution at $37^{\circ} \mathrm{C}$. is arrested by cooling to $32^{\circ} \mathrm{C}$. (Burn, 1958). Any factor that prolongs the refractory period of atrial muscle will tend to abolish these abnormal rhythms. Cooling has been shown to lengthen the duration of the action potential in cat papillary muscle (Trautwein and Dudel, 1954) and in atrial muscle (Marshall, 1957), and it is almost certain that the human atrium behaves in the same way. Other factors may contribute, such as alteration in vagal tone and reduction in acetylcholine formation in atrial muscle. It is clear that cooling the heart muscle brings into play a number of influences acting on the atrial rate and rhythm and that under certain circumstances, reproduced by chance in the course of these observations, the antifibrillatory action may become temporarily dominant and restore normal atrial conduction. When pronestyl was used, it may have helped in abolishing flutter by virtue of its effect in prolonging the refractory period of atrial muscle. Although this effect is less pronounced than on ventricular muscle at normal body temperature-a fact well-recognized in the clinical use of the drug-its antifibrillatory action may have been enhanced in the course of these observations since lowering the body temperature potentiates the action of many drugs in warm-blooded animals (Fuhrman, 1946; Haeger et al., 1957).

Hypothermia is not a consistent method of abolishing atrial fibrillation or flutter, and more experience is needed to find out whether the technique has any therapeutic possibilities.

Atrio-ventricular (A-V) dissociation in two patients gave way to sinus rhythm on immersion in cold water, before the œesophageal temperature had fallen from $37^{\circ} \mathrm{C}$. in one case and after a fall of $2^{\circ} \mathrm{C}$. in the other: neither had digitalis or quinidine beforehand. The current concept of A-V dissociation implies two pacemakers, one usually in the sinu-atrial node for the atria, and the other for the ventricles in the A-V node. Although impulses are formed slightly more rapidly in the A-V node, as in the two present cases, the atria do not respond to them because of the existence of a unidirectional atrial block. Sometimes a sinus impulse reaches the A-V node and junctional tissues 
after its refractory period and activates the node and the ventricle (interference beats, Fig. 6 and 7). Hypothermia restores conduction of the sinus impulses presumably by a greater depression of the A-V node and junctional tissues than the sinu-atrial node, so that now, each of the sinus impulses reaches the A-V node and junctional tissues after its refractory period and succeeds in activating it.

Premature beats, atrial and ventricular, often develop in the course of hypothermia (Johannson et al., 1956). For this reason, a man aged 47, with severe pulmonary stenosis and multiple ventricular premature beats which resisted all the established lines of therapy, was considered to be a risky candidate for hypothermia: yet the premature beats were abolished a few minutes after immersion. A suggested explanation is that the lowered temperature suppressed an ectopic ventricular focus, or alternately that the action potential of the ventricular muscle was lengthened by the lowered temperature and the ectopic stimulus acted when the muscle was still refractory. Burn (1959) conceives this situation as a lessening of the energy demand of the muscle by cooling, so that the available energy is better able to maintain normal function and to prevent the occurrence of premature beats.

\section{SUMMARY}

Observations were made on four different types of cardiac arrhythmias present in persons undergoing hypothermia (immersion technique: $37^{\circ}-30^{\circ} \mathrm{C}$.) prior to cardiac surgery.

Hypothermia produced the following changes in atrial fibrillation: slowing of the atrial and ventricular rates, and development of a precisely regular ventricular rate while the atria continued to fibrillate; and occasionally when the ventricular rate was slow, QRS complexes became wide and notched, suggesting an increasing degree of block in the conducting system or displacement of the pacemaker to one or other branch of the bundle of His or into a ventricle. Nodal or sinus rhythm was temporarily restored in 3 out of 13 patients with long-standing atrial fibrillation. Atrial fibrillation did not seem to predispose to ventricular fibrillation. Hypothermia restored sinus rhythm to one patient with atrial flutter, but failed to do so in another.

Atrio-ventricular dissociation with interference was abolished in two patients by slight lowering of the œsophageal temperature.

Multiple ventricular ectopic beats in one patient disappeared promptly on lowering the temperature a few degrees.

I am grateful to my colleagues in the Departments of Thoracic Surgery, Anæsthetics, and Cardiology and to Mr. E. Bridger who recorded the electrocardiograms.

\section{REFERENCES}

Burn, J. H. (1959). Personal communication.

L, and Goodford, P. J. (1957). J. Physiol., 137, $20 \mathrm{P}$.

Emslie-Smith, D. (1956). Aust. Ann. Med., 5, 62.

Fleming, P. R., and Muir, F. H. (1957). Brit. Heart J., 19, 59.

Fuhrman, F. A. (1946). Physiol. Rev., 26, 247

Graham, G. R. (1957). Verh. dtsch. Ges. Kreisl.-Forsch., 23, 79.

Haeger, K., Johansson, B., and Sjöström, B. (1957). Amer. Heart J., 53, 31.

Hicks, C. E., McCord, M. C., and Blount, S. G., Jr. (1956). Circulation, 13, 21.

Johansson, B., Biörck, G., Haeger, K., and Sjöström, B. (1956). Acta med. Scand., 155, 25

Marshall, J. M. (1957). Circulation Res., 5, 664.

Schott, A. (1959). Personal communication.

Sellick, B. A. (1957). Lancet, 1, 443.

Trautwein, W., and Dudel, J. (1954). Pflüg. Arch. ges. Physiol., 260, 104. 